Perspective

\title{
Can We Sustain Sustainability? A Critical Synthesis of Pertinent Literature
}

\author{
Jay L. Brand $1, *$ (i) and Sally Augustin ${ }^{2}$ \\ 1 Department of Leadership, Andrews University, Berrien Springs, MI 49104, USA \\ 2 Design with Science, Research Design Connections, La Grange Park, IL 60526, USA; \\ sallyaugustin@designwithscience.com \\ * Correspondence: brand@andrews.edu; Tel.: +1-269-471-3784
}

Citation: Brand, J.L.; Augustin, S. Can We Sustain Sustainability? A Critical Synthesis of Pertinent Literature. Sustainability 2021, 13, 12753. https://doi.org/10.3390/ su132212753

Academic Editors: Christina Bodin Danielsson,

Francesco Pomponi and Marc A. Rosen

Received: 26 July 2021

Accepted: 16 November 2021

Published: 18 November 2021

Publisher's Note: MDPI stays neutral with regard to jurisdictional claims in published maps and institutional affiliations.

Copyright: (C) 2021 by the authors. Licensee MDPI, Basel, Switzerland. This article is an open access article distributed under the terms and conditions of the Creative Commons Attribution (CC BY) license (https:/ / creativecommons.org/licenses/by/ $4.0 /)$.

\begin{abstract}
Architects and designers, along with their corporate clients, generally embrace the importance of environmental stewardship, saving the earth's ecosystem, and sustainable design. However, research is needed to link sustainable design with relevant human behavior (e.g., in corporate offices and educational settings) to ensure its enduring legacy. Regarding changing people's behavior, the majority of human experience results from unconscious processes, i.e., brain-environment interactions not available to awareness; thus, in general, people cannot articulate the nature of these associations. Using theoretical roots stemming from William James and running through ecological psychology (e.g., James J. Gibson to Roger Barker), Harry Heft has argued that the influence of environmental design precedes conscious awareness and information processing. Assuming Heft's conjecture, this implies that - if informed by biologically influential signals (e.g., biophilic design)— the design of the ambient physical environment may positively 'nudge' human behavior in ways useful to sustainability and sensitivity to the environment-although relevant critical perspectives suggest that dynamic conditions and contextual complexity may modify the potential of nudge theory applications. Still, could it be that sustainable design can improve human health and well-being? Research suggests that environmentally responsible and biophilic design may accomplish at least a few elements of this goal and perhaps also enhance some aspects of cognitive performance. Could this approach support environmental sustainability by linking sustainable design to its potential economic benefits via worker productivity or student success? If so, then the strategy of improving positive well-being through design aligns well with the goal of maintaining the long-term viability of the earth's ecosystem.
\end{abstract}

Keywords: organizational strategy; sustainable design; environmental psychology; information processing; well-being; performance; biophilic design; nudge theory

\section{Introduction}

Although many organizations, institutions, corporate leaders, and both national and international enterprises claim to embrace sustainability, sustainable design, green design, and saving the environment in general, fewer consistently reflect this dedication in practice [1]. Thus, there often appears to be a discrepancy between intentions with regard to sustainable or 'green' design and actual practice and behavior. However, given our fragile dependency on the earth's continued ability to nurture life [2,3], it seems only logical to elevate such concerns to the level of a moral imperative. In this regard, the Gaia hypothesis [4,5], the privileged planet [6], and other theoretical perspectives offer different approaches to understanding why our planet appears to be well-designed to support various kinds of life. Regardless of which broad theoretical framework undergirds a genuine concern for preserving the environment globally, a commitment to preserving the earth's capacity to sustain life represents a reasonable priority that has proved difficult to address due to a, perhaps inevitable, conflict between national (regional) and international (global) interests. 
In any case, maintaining the quality of life for future generations constitutes a compelling moral basis for sustainable environmental design. Thus, we should not sacrifice the well-being of future inhabitants of the earth in order to meet the preferences of its current occupants (e.g., by exploiting scarce environmental resources). Yet neither should we compromise the needs of people living now to ensure those identical goals for future residents, because 'A kingdom divided against itself cannot stand.' Sustainability and 'green design', then, should reflect a consistent set of values that determine both current and future design principles and priorities. Ideally, these principles should endeavor to achieve outcomes defined and measured by well-being and quality of life for earth's denizens, along with associated economic benefits.

\subsection{Relevant Human Information Processing (Cognition)}

Accepting for the moment that well-being and quality of life for both future and current populations form primary concerns for the design of the built environment, how can said design best contribute to these consequences? To explore this question, we must examine some aspects of human perception and cognition that underlie how we experience the environment around us. Painting with a very broad brush, as we develop, our sensory experience of the world generates memories that operate like perceptual categories to classify future experience [7]. In this way, past experience can bias our interpretation of current and future experience. As the environment always provides the context for these experiences, the design of that environment contributes to the quality of such experiences (cf. 'cue-dependent' learning and memory, [8,9]).

A very important question for sustainable design focused on human well-being and quality of life concerns the level of conscious awareness associated with these various aspects of perceptual processing. Due to the fact that well-being, quality of life, and related characteristics of experience tend to be defined subjectively (e.g., self-report), then conscious awareness of environmental influences on such subjective experience would appear to be important, if not crucial, for guiding their design. Indeed, what we notice about our immediate environment is determined by selective attention [10]. This attentional process involves resonance between neural activity in the thalamus and cortical sensory processing areas; such resonance or feedback serves to prioritize some objects or patterns in the sensory input over others [11]. Certainly, selective attention must be partly voluntary, because it can be affected by intrinsic factors (e.g., conscious strategies); however, it can also be influenced by various extrinsic (e.g., object-related) factors, suggesting that what gets noticed and consciously interpreted in the environment might be jointly determined by past experience (through selective attention and perceptual categories, cf. Posner, 2011 [10]) and design.

\subsection{Design Influence without Awarness}

Perhaps a more promising role for environmental design in improving the quality of experience rests on the mostly unconscious, autonomous interaction between the physical context and subjective awareness. Psychologists have long known that the vast majority of the determinants of subjective experience remain unconscious [12]. Although most contemporary cognitive scientists may significantly qualify Freud's original theoretical views of the unconscious mind, most researchers accept the salience of unconscious (i.e., outside of or 'beneath' awareness) processes in such important functions as sensation, perception, attention, and memory [13]. These functions substantially contribute to well-being and quality of life through their mostly autonomous association with emotions [14]. These mutual dependencies between cognition and emotion represent fertile areas of concern for improving well-being and quality of life generally.

If the majority of mental processes remain unavailable to conscious awareness, then the design of the environment may play an important role in positive emotional experience (e.g., well-being and quality of life). Harry Heft [15] described the theoretical potential for unconscious processing of the environment to influence the quality and efficiency of expe- 
rience. Beginning with William James' cogent descriptions of the features of consciousness and selective attention, especially their 'pre-conscious' potency, Heft integrated Eleanor and James Gibson's ecological theory of perception [16] to illustrate the latent impact of the environment on perception and cognition. Heft wove the element of time into the process of experiencing design by leveraging Roger Barker's view of the interaction between cognition and its context as an event. Thus, somewhat broader, psychosocial aspects of environmental design, including corporate culture (cf. Schein and Schein, 2016 [17]) may figure prominently in people's individual experience as occupants of place(s) or as employees of organizations.

The importance of Heft's theoretical exploration involves its support of the possibility that the environment's influence on the quality and effectiveness of cognition (e.g., attention, memory, emotional regulation) occurs prior to any detailed sense of awareness of one's surroundings. Dependent somewhat on individual occupants' past experiences (due to their idiosyncratic, interpretive 'perceptual categories'), the design of the environment can provide a consistently positive effect on cognitive performance and subjective experience. Assuming this explanation enjoys some level of credibility, a few important practical consequences follow. First, traditional 'design charrettes' may not discover the most helpful insights for informing the design of a particular physical environment (e.g., work or residential), because, by definition, such focus groups acquire consciously interpreted and intentionally articulated observations, persuaded somewhat by the process of reaching consensus.

\subsection{Design Methods for Organizational Benefit}

Informed by this line of reasoning, empirical investigations of predictive associations between aspects of design and the quality and effectiveness of experience [18-20] represent a more fertile approach for improving the design of the built environment than more typical 'design charrettes' or focus groups-particularly over the long term. Such a prospective vision for environmental design research aligns well with sustainable values, because such methods would improve the alignment between the design of the built environment (e.g., for office employees, especially 'knowledge workers', as well as students in schools) and human preferences. This approach would tend to recruit environmental design for improving the quality of human experience (e.g., well-being), ensuring that design could make important contributions to the earth's capability to support and nurture life-especially for future generations.

Grounding environmental design within the topics of quality of life, health, and well-being ensures its place at the strategic table for sustainable design, preserving the planet, and protecting earth's ecosystems-considered both locally and globally. One relevant perspective that enjoys a great deal of practical relevance has been termed 'nudge' theory [21]. For example, if sustainable, environmentally friendly alternatives are designed as the 'default' for employees, without necessarily realizing it, they will be more likely to make choices that benefit the environment (e.g., if paper straws are easier to find and reach than plastic straws, people will tend to select paper straws for their drinks). 'Nudge' theory can also improve employee health and well-being through similar applications (e.g., if workplace designers place water or more healthy drinks (i.e., containing less refined sugar) so that they are easiest for employees to see and to reach, employees will be more likely to select these when they choose a drink).

However, salient critical perspectives suggest that misalignments among the implementation of nudging, conceptions of sustainability, organizational values, and corporate strategy can serve to modify nudging's potential for positive influence and practical benefits [22]. For example, individual and organizational interpretations of the use of 'nudging' as a corporate strategy for design, governance and sustainability may differ if considered at a macro-political or micro-behavioral level of analysis [23]. Additionally, Snowden et al.'s Cynefin model for decision making, to help leaders make sense of these multiple, mutually interacting factors, depends on the proposal that organizations' historic acceptance 
of scientific management theory must be broadened to embrace complexity theory and complex/chaotic systems. Snowden et al. developed their model to help leaders manage under dynamic, contingent contexts [24].

Yet, if implemented under appropriate leadership conditions, such as suggested by relevant cognitive neuroscience [25] and within facilitative contexts, these frameworks and methods might achieve design's potential to improve individual subjective experience and performance. If integrated collectively across populations (e.g., of employees), addressing human preferences and prioritizing comfort in the design of the built environment would result in fewer 'moves, adds and changes' post-construction, reducing costs and any associated impacts on the environment (e.g., lower landfill waste).

Furthermore, more comfortable employees (or residents of any designed and constructed place or location) would tend to be more satisfied, and satisfied employees might be less likely to leave, benefiting the success and longevity of their institutions and organizations. This vantage point includes corporate sustainability in the conceptual framework of design for sustainability, although organizational longevity, per se, is rarely adopted as an important corollary of environmental sustainability-dependent of course on the values, practices, and environmental footprint of such corporations.

In this regard, Hansen and Schaltegger offered a conceptual framework developed from their investigation of research on sustainability balanced scorecard (SBSC) measures to assess organizational outcomes [26]. Their theoretical approach examined the consequences of integrating organizational values and corporate sustainability strategy for performance and strategic objectives. Guided by their review of this literature, instrumental, social/political, and normative theoretical perspectives informed the structure of their model. In any case, as Andrea Gabor explained, invariably, one of the top four characteristics of organizations that thrive across many decades emphasizes their concern for environmental preservation-in addition to their focus on nurturing employee development, experimentation and innovation, and preserving capital reserves [27] (see Figure 1).

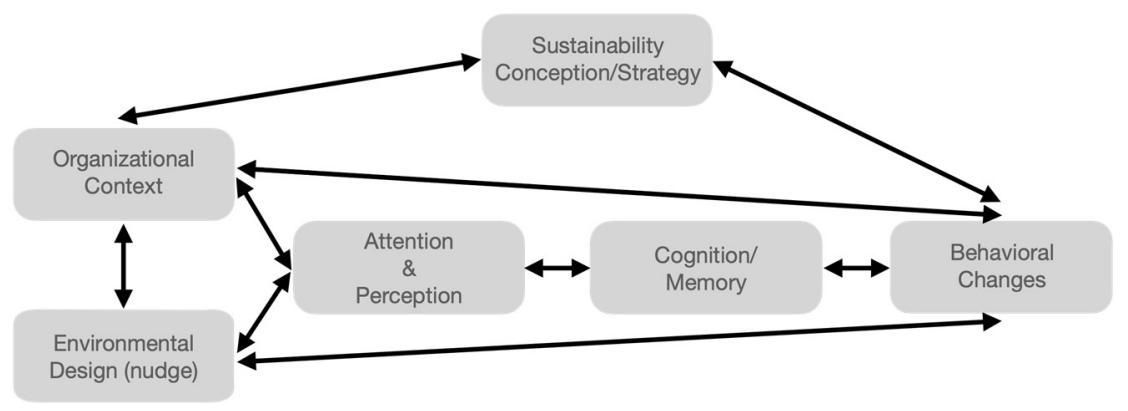

Figure 1. An interactive model based on the critical synthesis of pertinent literature reviewed.

\subsection{Relevant Empirical Research Support}

Somewhat more prosaically, neuroscience research offers clear and compelling evidence for positive cognitive and emotional implications of experiencing environmentally responsible design. For example, Allen and colleagues [28], after an extensive literature review, reached the conclusion that green buildings benefited human health and that people working in green buildings were more satisfied with aspects of their physical work environments than people working in other sorts of buildings. Additionally, productivity seemed to enjoy a boost in green buildings. In addition, Allen and teammates determined that employee tenure was longer when they worked in green buildings, while the time to fill open positions was shorter. The same group recorded improved quality of care in environmentally responsible healthcare facilities.

Similarly, Leaman and Bordass [29] reported that people working in environmentally responsible buildings feel better about the image projected by their building than people working in other structures and also seem to be more tolerant of comfort-related problems (e.g., temperature and ventilation concerns) than people working in conventional buildings 
are of similar conditions. Cranz and colleagues [30], via a literature review, came to the conclusion that being linked to a green building increases humans' psychological well-being.

In general, green design seems to be positively received. Sorqvist, Haga, Holmgren, and Hansla [31] shared that their empirical research has shown that green products have a 'halo effect'; a lamp labeled as 'environmentally friendly', for example, was seen as more comfortable to use than an identical lamp labeled 'conventional' and professional performance was better in the condition perceived as more comfortable. Task performance was objectively measured; thus, differences reported were not merely due to differences in perceptions of study participants.

Cognitive Performance. MacNaughton and teammates [32] found that, compared to people working in less environmentally friendly structures, employees in green buildings with exceptional ventilation systems (those that surpassed ASHRAE Standard 62.1-201, for example) performed better on tests of decision-making performance, which served as proxies for cognitive performance more generally. In the green buildings, performance on the cognitive tests (i.e., the decision making tasks) was $26.4 \%$ higher than in the conventional structures and sick building symptom levels were 30\% lower.

Furthermore, by studying people who worked in a green environment for six full days, Allen and colleagues [33] learned that higher-order cognitive function was enhanced in the environmentally responsible structure. Performance in multiple buildings was compared, in some structures, termed 'Conventional', volatile organic compound levels were high, in 'Green' buildings VOC levels were low, and in 'Green+' structures, outside air ventilation rates were 'high'. Allen and colleagues found that cognitive performance scores were dramatically higher in the green structures; $61 \%$ higher for the Green building and 101\% greater in the Green+ areas, compared to performance in the 'Conventional' spaces. At the sorts of carbon dioxide levels regularly found in indoor spaces (approximately $950 \mathrm{ppm}$ ), performances on seven of the nine cognitive tests administered were lower than on the same tests at lower concentrations of carbon dioxide. Cognitive functions tested included decision making, developing strategies, and responding to crises. Participants in this study had a range of backgrounds, including design and architecture, computer programming and engineering, as well as marketing and general management.

Occupant Satisfaction. Providing further support for the claim that 'green buildings' and 'sustainable design' improve occupancy quality, the General Services Administration conducted a post-occupancy evaluation of 12 environmentally responsible buildings in its portfolio [34]. The researchers determined that employees working in the GSA's buildings had higher satisfaction levels and the researchers felt these higher occupant satisfaction scores were particularly meaningful as greater occupant satisfaction had been linked to enhanced individual and team performance.

Reaching similar conclusions, Leder, Newsham, Veitch, Mancini, and Charles [35] also conducted a large field study, collecting data in green and conventional buildings. They reported that they determined that people working in green buildings where they collected data had higher levels of environmental satisfaction generally and that this was highly desirable as enhanced indoor environments have been tied to more positive scores on job satisfaction and other organizational performance measures.

In addition, Newsham, Birt, Arsenault, Thompson, Veitch, Mancini, Galasiu, Gover, Macdonald, and Burns [36] conducted a post-occupancy review of twelve green buildings in Canada and the northern United States and found that those green buildings earned higher environmental satisfaction scores than conventional ones, as well as better evaluations on subscales related to, for example, outdoor views, aesthetics, mood experienced, and workplace image.

Organizational Benefits. Offering complementary findings defined at the organizational level, Bangawal, Tiwari, and Chamola linked green design to organizational commitment, via job satisfaction [37]. Adding to these compelling results related to organizational effectiveness, Newsham, Veitch, and $\mathrm{Hu}$ [38] thoroughly investigated the consequences of working in green buildings. This Newsham-led team also linked working 
in green buildings to job satisfaction and corporate engagement, for example, with those in green workplaces scoring better on these factors than individuals in conventional ones. Newsham, Veitch, and Hu suggested that employees know if their workplaces are LEED certified or not.

Educational Environments. Most of the prior investigations have focused on business or corporate enterprise environmental contexts. Nevertheless, these mostly positive outcomes appear to generalize to educational/learning contexts as well. For example, green school design also appears to benefit users. Kats [39] reports 3-5\% improvements in test scores for pupils at green schools when compared to the performance of pupils in conventional schools.

Some Contrary Evidence. However, compared to this host of compellingly favorable findings, Urban and Sailer [40] obtained somewhat different results when they studied links between workplaces with green building certification and occupant satisfaction. Data from a post-occupancy evaluation at a certified office building indicated that a high Green Building rating is not necessarily tied to high levels of employee satisfaction with the environments provided. These somewhat surprisingly contrary results may reflect truncated ranges in the data measuring either dimensions of building performance, occupant satisfaction, or both. Nonetheless, at the very least, this study demonstrates that exceptions to the otherwise well-established link between green, sustainably designed buildings and various measures of occupancy quality and organizational outcomes do exist.

\subsection{Biophilic Design}

Biophilia represents a compelling theoretical framework relevant to green/sustainable design; this perspective stresses contact with, access to, and reflection of nature and natural elements in the experience(s) of building occupants. In this regard, via a literature review of research done with non-residential buildings, Cole, Coleman, and Scannell [41] linked positive affect with biophilic design, although some usual features of environmentally responsible construction, such as hard surfaces and natural ventilation, may degrade place attachment. Place attachment is an important issue because it has been tied to wellbeing. The Cole-led team indicated that designers may attempt to boost place attachment via connections to nature and physiological comfort. These findings suggest that at least some attributes typically associated with green/sustainable design (e.g., uniformly open spaces, predominantly hard surfaces) may need to be reconsidered in pursuit of ideal human occupancy quality and experience.

'Green' Products. In light of a recent exploration in this regard, the positive effect(s) on users from green, sustainable designs for buildings appear to extend to the use of green or environmentally friendly products as well. Tezer and Bodur [42] studied the emotional implications of using green products, linking this use to a boost in pleasure in use, even when the user has not selected the product that they are utilizing, as long as the negative environmental implications of the green feature is above a minimal level.

\subsection{Future Considerations}

Finally, instilling meaning and purpose into organizational success by aligning corporate values with the personal values of employees and clients represents an often-neglected key to organizational growth and longevity [43]. Genuinely embedding organizational strategy within the broader, more consequential goal of preserving the planet and the quality of earth's environment can serve to increase employee loyalty and engagement-not to mention customer loyalty and associated advantages.

This conceptual framework for interpreting sustainable design of the built environment by linking cognitive and ecological psychology within the broader goals of environmental sustainability could be complemented by more rigorous analytical approaches for evaluating the symbolic communication of the visual aspects of such designs [44]. Thus, future research might consider how visual images of sustainable design distinguish it from alternatives and communicate its potential value and benefits to relevant 
stakeholders. Additionally, as literature linking human information processing, cognitive science, 'nudge' theory, sustainability, and environmental design evolves, a bibliometric evaluation of this developing interdisciplinary field could help to frame its empirical and theoretical boundaries [45].

Author Contributions: Conceptualization, J.L.B. and S.A.; investigation, J.L.B. and S.A.; original draft preparation, J.L.B. and S.A.; writing-review and editing, J.L.B. and S.A. All authors have read and agreed to the published version of the manuscript.

Funding: This research received no external funding.

Institutional Review Board Statement: Not applicable.

Informed Consent Statement: Not applicable.

Data Availability Statement: Not applicable.

Conflicts of Interest: The authors declare no conflict of interest.

\section{References}

1. Seidel, S.; Recker, J.; Pimmer, C.; vom Brocke, J. Enablers and barriers to the organizational adoption of sustainable business practices. In Proceedings of the 16th America's Conference on Information Systems: Sustainable IT Collaboration around the Globe, Lima, Peru, 12-15 August 2010; Association for Information Systems: Atlanta, Georgia, USA, 2010 ; pp. 1-10.

2. Attenborough, D. A Life on our Planet: My Witness Statement and a Vision for the Future; Grand Central Publishing: New York, NY, USA, 2020.

3. Wilson, E.O. Consilience: The Unity of Knowledge; Alfred A. Knopf: New York, NY, USA, 1998.

4. Lovelock, J. Gaia: A New Look at Life on Earth, Illustrated ed.; Oxford University Press: Oxford, UK, 2016.

5. Rubenstein, E. The Gaia Hypothesis: Cultivated Man/Natural Planet; Thriftbooks: Chicago, IL, USA, 2019.

6. Gonzalez, G.; Richards, J.W. The Privileged Planet: How Our Place in the Cosmos is Designed for Discovery; Regnery: Washington, DC, USA, 2004.

7. Sloutsky, V. From perceptual categories to concepts: What develops? Cogn. Sci. 2010, 34, 1244-1286. [CrossRef]

8. Eich, J.E. The cue-dependent nature of state-dependent retrieval. Mem. Cogn. 1980, 8, 157-173. [CrossRef] [PubMed]

9. Tulving, E. Elements of Episodic Memory, Revised ed.; Oxford University Press: Oxford, UK, 1985.

10. Posner, M.I. (Ed.) The Cognitive Neuroscience of Attention, 2nd ed.; Guilford Press: New York, NY, USA, 2011.

11. LaBerge, D. Attentional Processing: The Brain's Art of Mindfulness; Harvard University Press: Cambridge, MA, USA, 1995.

12. Bargh, J.A.; Chartrand, T.L. The unbearable automaticity of being. Am. Psychol. 1999, 54, 462-479. [CrossRef]

13. Poeppel, D.; Mangun, G.R.; Gazzaniga, M.S. The Cognitive Neurosciences, 6th ed.; MIT Press: Cambridge, MA, USA, 2020.

14. Damasio, A. The Feeling of What Happens: Body and Emotion in the Making of Consciousness; Mariner Books: Boston, MA, USA, 2000.

15. Heft, H. Ecological Psychology in Context: James Gibson, Roger Barker, and the Legacy of William James's Radical Empiricism; Routledge: New York, NY, USA, 2001.

16. Gibson, J.J. The Senses Considered as Perceptual Systems; Houghton-Mifflin: Boston, MA, USA, 1966.

17. Schein, E.; Schein, P. Organizational Culture and Leadership, 5th ed.; John Wiley \& Sons: Hoboken, NJ, USA, 2016.

18. Stamps, A.E. Mystery, complexity, legibility and coherence: A meta-analysis. J. Environ. Psychol. 2004, 24, 1-16. [CrossRef]

19. Stamps, A.E. Psychology and the Aesthetics of the Built Environment; Springer Science + Business Media: New York, NY, USA, 2013.

20. Augustin, S. Place Advantage: Applied Psychology for Interior Architecture; John Wiley \& Sons: Hoboken, NJ, USA, 2009.

21. Miller, R.; Williams, P.; O'Neill, M. The Healthy Workplace Nudge: How Healthy People, Culture, and Buildings Lead to High Performance; Wiley: Hoboken, NJ, USA, 2018.

22. Borneman, B.; Burger, P. Nudging to sustainability? Critical reflections on nudging from a theoretically informed sustainability perspective. In Handbook of Behavioural Change and Public Policy; Handbook of Research on Public Policy Series; Straßheim, H., Beck, S., Eds.; Edward Elgar Publishing Ltd.: Cheltenham, UK, 2019; pp. 209-226.

23. Tyers, R. Macro libertarianism and micro paternalism: Governance in an age of nudging. In Handbook of Behavioural Change and Public Policy; Handbook of Research on Public Policy Series; Straßheim, H., Beck, S., Eds.; Edward Elgar Publishing Ltd.: Cheltenham, UK, 2019; pp. 332-343.

24. Snowden, D.J.; Boone, M.E. A leader's framework for decision making. Harv. Bus. Rev. 2007, 85, 68.

25. Rock, D.; Schwartz, J. The Neuroscience of Leadership. J. Strength-Based Interv. 2007, 16, 10-17.

26. Hansen, E.G.; Schaltegger, S. The sustainability balanced scorecard: A systematic review of architectures. J. Bus. Ethics 2016, 133, 193-221. [CrossRef]

27. Gabor, A. The Capitalist Philosophers: The Geniuses of Modern Business-Their Lives, Times and Ideas; Crown Business: New York, NY, USA, 2000.

28. Allen, J.; MacNaughton, P.; Laurent, J.; Flannigan, S.; Eitland, E.; Spengler, J. Green buildings and health. Curr. Environ. Health Rep. 2015, 2, 250-258. [CrossRef] 
29. Leaman, A.; Bordass, B. Are users more tolerant of 'green' buildings. Build. Res. Inf. 2007, 35, 662-673. [CrossRef]

30. Cranz, G.; Lindsay, G.; Morhayim, L.; Lin, A. Communicating sustainability: A postoccupancy evaluation of the David Brower Center. Environ. Behav. 2014, 46, 826-847. [CrossRef]

31. Sorqvist, P.; Haga, A.; Holmgren, M.; Hansla, A. An eco-label effect in the built environment: Performance and comfort effects of labeling a light source environmentally friendly. J. Environ. Psychol. 2015, 42, 123-127. [CrossRef]

32. MacNaughton, P.; Satish, U.; Laurent, J.; Flanigan, S.; Vallarino, J.; Coull, B.; Spengler, J.; Allen, J. The impact of working in a green certified building on cognitive function and health. Build. Environ. 2017, 114, 178-186. [CrossRef]

33. Allen, J.; MacNaughton, P.; Satish, U.; Santanam, S.; Vallarino, J.; Spengler, J. Associations of cognitive function scores with carbon dioxide, ventilation, and volatile organic compound exposures in office workers: A controlled exposure study of green and conventional office environments. Environ. Health Perspect. 2016, 124, 805-812. [CrossRef] [PubMed]

34. General Services Administration Public Buildings Service, Office of Applied Science. Assessing Green Building Performance: A Post Occupancy Evaluation of 12 GSA Buildings. 2008. Available online: https:/ / www.usgbc.org/resources/assessing-greenbuilding-performance-post-occupancy-evaluation-12-gsa-buildings (accessed on 30 November 2019).

35. Leder, S.; Newsham, G.; Veitch, J.; Mancini, S.; Charles, K. Effects of office environment on employee satisfaction: A new analysis. Build. Res. Inf. 2016, 44, 34-50. [CrossRef]

36. Newsham, G.; Birt, B.; Arsenault, C.; Thompson, A.; Veitch, J.; Mancini, S.; Galasiu, A.; Gover, B.; Macdonald, I.; Burns, G. Do 'green' buildings have better indoor environments? New evidence. Build. Res. Inf. 2013, 41, 415-434. [CrossRef]

37. Bangwal, D.; Tiwari, P.; Chamola, P. Workplace design features, job satisfaction, and organizational commitment. Sage Open 2017, 7, 2158244017716708. [CrossRef]

38. Newsham, G.; Veitch, J.; Hu, V. Effects of green building certification on organizational productivity metrics. Build. Res. Inf. 2018, 46, 755-766. [CrossRef]

39. Kats, G. Greening America's Schools: Costs and Benefits. 2006. Available online: https://www.usgbc.org/resources/greeningamerica039s-schools-costs-and-benefits (accessed on 21 October 2018).

40. Urban, M.; Sailer, K. Checking a green building myth-The relation of occupant satisfaction and rating levels in offices. In Proceedings of the 1st Transdisciplinary Workplace Research Conference, Tampere, Finland, 19-21 September 2018; Transdisciplinary Workplace Research Network: Tampere, Finland, 2018; pp. 47-48.

41. Cole, L.; Coleman, S.; Scannell, L. Place attachment in green buildings: Making the connections. J. Environ. Psychol. 2021, in press. [CrossRef]

42. Tezer, A.; Bodur, H. The green consumption effect: How using green products improves consumption experiences. J. Consum. Res. 2020, 47, 25-39. [CrossRef]

43. Brand, J.L. Leadership and organizational dynamics. J. Appl. Christ. Leadersh. 2021, in press.

44. Raaphorst, K.; Roeleveld, G.; Duchhart, I.; Van der Knaap, W.; Van den Brink, A. Reading landscape design representations as an interplay of validity, readability and interactivity: A framework for visual content analysis. Vis. Commun. 2018, 19, 163-197. [CrossRef]

45. Rahanen, L.; Weiler, B.; Moyle, B.D.; McLennan, C.J. Trends and patterns in sustainable tourism research: A 25-year bibliometric analysis. J. Sustain. Tour. 2015, 23, 517-535. [CrossRef] 